\title{
Veno-Venous Extracorporeal Membrane Oxygenation for Acute Lung Injury after Surgery for Aortic Dissection: A Case Report
}

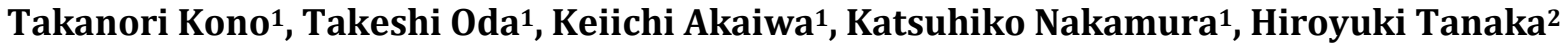 \\ ${ }^{1}$ Department of Cardiovascular Surgery, Omura Municipal Hospital, Nagasaki, Japan \\ ${ }^{2}$ Department of Surgery, Kurume University School of Medicine, Fukuoka, Japan \\ Email:kono_takanori@med.kurume-u.ac.jp, oda@jadecom.jp, akaiwa@med.kurume-u.ac.jp, katsuhikon@jadecom.jp, \\ htanaka@med.kurume-u.ac.jp
}

How to cite this paper: Kono, T., Oda, T., Akaiwa, K., Nakamura, K. and Tanaka, H. (2017) Veno-Venous Extracorporeal Membrane Oxygenation for Acute Lung Injury after Surgery for Aortic Dissection: A Case Report. World Journal of Cardiovascular Surgery, 7, 156-163.

https://doi.org/10.4236/wjcs.2017.712018

Received: November 25, 2017

Accepted: December 12, 2017

Published: December 15, 2017

Copyright () 2017 by authors and Scientific Research Publishing Inc. This work is licensed under the Creative Commons Attribution International License (CC BY 4.0).

http://creativecommons.org/licenses/by/4.0/

\begin{abstract}
Acute respiratory failure after surgery for aortic dissection is a serious complication that has been associated with increased mortality and morbidity. Veno-venous (VV) extracorporeal membrane oxygenation (ECMO) is reported as one of the treatments for this life-threatening complication. A 78year-old male patient was admitted to our hospital for Stanford type A acute aortic dissection. He underwent emergency replacement of the ascending aorta, after which he developed acute lung injury. It was difficult to maintain oxygenation with a respirator mask. Therefore, VV-ECMO was initiated on postoperative day 1 . The oxygenation gradually improved, and VV-ECMO was continued until postoperative day 13 . On postoperative day 25 , mechanical ventilation was withdrawn. The patient was discharged from the hospital on postoperative day 149. We report a case of successful treatment of acute lung injury with VV-ECMO initiated after surgery for aortic dissection. VVECMO can be considered as a treatment option for severe acute lung injury after surgery for aortic dissection.
\end{abstract}

\section{Keywords}

Acute Aortic Dissection, Cardiopulmonary Bypass, Cardiothoracic Surgery, Acute Lung Injury, Extracorporeal Membrane Oxygenation

\section{Introduction}

The surgical outcomes for type A acute aortic dissection have improved due to recent advances in operative methods, extracorporeal circulation assistive devic- 
es, postoperative management strategies, and the quality of vascular prostheses [1] [2]. However, acute aortic dissection can cause severe respiratory failure due to systemic inflammatory response syndrome and acute lung injury (ALI). These complications have been associated with increased morbidity and mortality [2].

In patients who develop ALI after surgery for aortic dissection, mechanical ventilation may be insufficient to maintain the respiratory function. Extracorporeal membrane oxygenation (ECMO) has been reported to provide effective circulatory and respiratory support to patients with acute cardiac and respiratory failure that is refractory to mechanical ventilation [3]. However, there have only been a few reports on the use of veno-venous (VV) ECMO for acute respiratory failure after cardiac surgery [3] [4] [5]. Here, we report the survival case of a patient who received VV-ECMO for ALI after surgery for aortic dissection.

\section{Case Presentation}

A 78-year-old male patient was taken to our hospital by ambulance due to chest oppression during agricultural practice. The patient took apixaban $(5 \mathrm{mg} /$ day) for paroxysmal atrial fibrillation. His height, body weight, and body surface area were $173 \mathrm{~cm}, 74 \mathrm{~kg}$, and $1.88 \mathrm{~m}^{2}$, respectively. Computed tomography showed aortic dissection starting from the ascending aorta extending into the bilateral common iliac arteries as well as pericardial effusion accumulation (Figure 1).
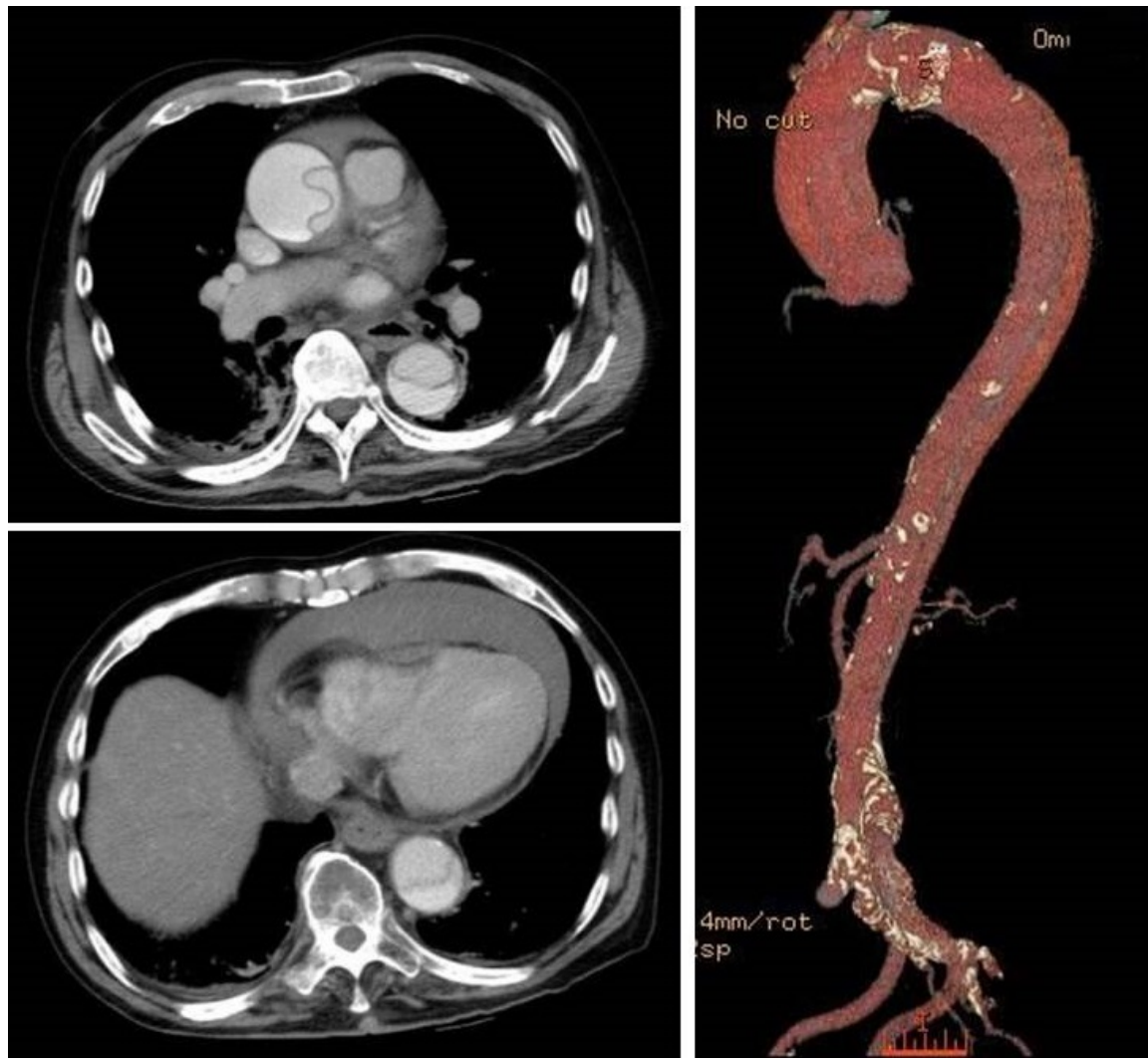

Figure 1. Preoperative computed tomography showed aortic dissection (DeBakey I) and pericardial effusion accumulation. 
A diagnosis of Stanford type A acute aortic dissection was made. Emergency life-saving surgery was performed. Cardiopulmonary bypass was established via the right axillary artery and the left common femoral artery (inflows) and right atrial cannulation (outflow). To protect the brain, selective cerebral perfusion and hypothermic circulatory arrest with a rectal temperature of $25^{\circ} \mathrm{C}$ were used. We removed the initial tear located at the proximal aortic arch and performed ascending and hemi-aortic arch replacement. Operative time, cardiopulmonary bypass time, aorta clamp time, and circulatory arrest time were $8 \mathrm{~h} 40 \mathrm{~min}, 4 \mathrm{~h}$ $38 \mathrm{~min}, 2 \mathrm{~h} 27 \mathrm{~min}$, and $1 \mathrm{~h} 46 \mathrm{~min}$, respectively.

Hemostasis was time-consuming because of the effect of apixaban. The postoperative hemodynamic status was stable, especially after the bleeding was controlled. However, the oxygenation had been poor (barely enough to maintain 60 - $80 \mathrm{mmHg}$ of partial pressure of arterial oxygen $\left[\mathrm{PaO}_{2}\right] /$ fraction of inspiratory oxygen $\left[\mathrm{FiO}_{2}\right]$ ) since the admission into the high care unit. Administration ofa neutrophil elastase inhibitor had been started intraoperatively to improve oxygenation. Continuous hemodiafiltration was established because of oliguria; however, no improvement of oxygenation was observed. Instead, $\mathrm{PaO}_{2} / \mathrm{FiO}_{2}$ dropped to $40-50 \mathrm{mmHg}$. Cardiac index was $2.3 \mathrm{~L} / \mathrm{min} / \mathrm{m}^{2}$ and the blood pressure was maintained under using inotropic agents without intra-aortic balloon pumping. Finally, VV-ECMO was established under venous drainage from the left femoral vein using a 16.5-Fr $(15-\mathrm{cm})$ catheter; the tip of catheter was inserted into the left common iliac vein and arterialized blood was returned to the right atrium via a $21-\mathrm{Fr}(50-\mathrm{cm})$ catheter inserted from the right femoral vein. Pump flow was $2.0-2.4 \mathrm{~L} / \mathrm{min}$, and pump speed was around 1600 revolutions/ min (rpm). Intensive treatment including VV-ECMO was continued, and the oxygenation gradually improved. However, VV-ECMO could not be withdrawn. On postoperative day 10, we exchanged the circuit of VV-ECMO due to thrombotic deposits in the membrane oxygenator, and steroid pulse therapy (highdose methylprednisolone) was administered for three days at the dosage of 1 g/day. The respiratory condition improved afterwards, and VV-ECMO was withdrawn on postoperative day 13. A tracheotomy was performed on postoperative day 15 for aspiration of sputum. The dialysis treatment and mechanical ventilation were withdrawn on postoperative day 21 and 25, respectively. He was discharged from the hospital on postoperative day 149 . He is doing well 15 months after the surgery. Figure 2 shows the acute phase of the postoperative process.

\section{Discussion}

In addition to the direct effects of acute aortic dissection on the lung, ischemia-reperfusion injury and the release of large amounts of inflammatory mediators during cardiopulmonary bypass and circulatory arrest [6] as well as transfusion [7] contribute to ALI after cardiac surgery. ALI is a severe condition that can lead to death after cardiopulmonary bypass, with mortality rates ranging from $30 \%$ to $80 \%$ [8]. Here, we report a case of successful treatment of ALI 


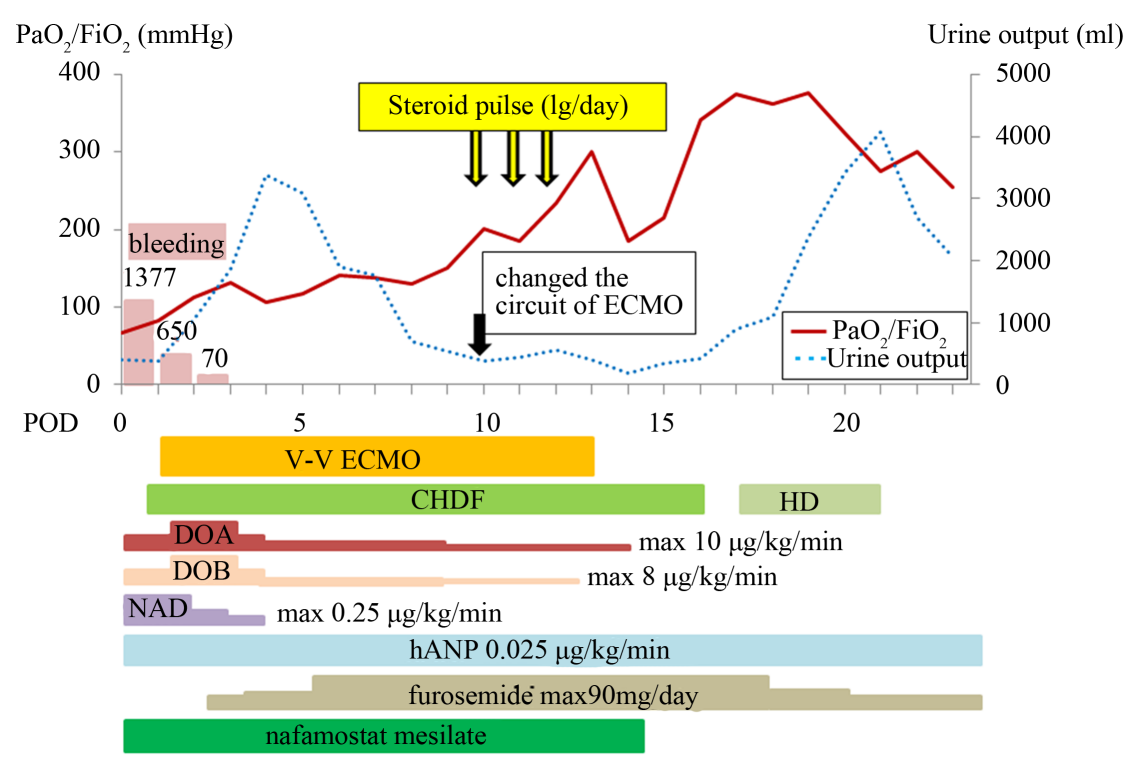

Figure 2. The acute phase of the postoperative process. CHDF: Continuous hemodiafiltration; DOA: Dopamine; DOB: Dobutamine; hANP: Human atrial natriuretic peptide; HD: Hemodialysis; NAD: Noradrenaline; VV-ECMO: Veno-venous extracorporeal membrane oxygenation.

with VV-ECMO initiated after surgery for aortic dissection.

VV-ECMO has been used to treat adults with severe respiratory failure effectively since the 1970s [9]. Two randomized trials have shown that VV-ECMO is not superior to conventional treatments [9] [10]. However, there have been many reports on the effectiveness of VV-ECMO for the treatment of adults with severe respiratory failure [11] [12]. There are also some reports on the usefulness of ECMO for severe respiratory failure after cardiovascular surgery [3] [4] [5]. Another technique of extracorporeal life support is veno-arterial (VA) ECMO. If the purpose is to oxygenate or remove carbon dioxide, VV-ECMO must be adapted. For circulatory collapse, VA-ECMO is mandatory [13]. Although VAECMO can offer hemodynamic support for a cardiogenic cause of hypotension, the primary disadvantages of VA-ECMO are increased risk of stroke, bleeding, renal failure, and Harlequin syndrome (selective lower body oxygenation with upper body hypoxia) [14]. Schmid et al. described the following general indications for VV-ECMO: $\mathrm{PaO}_{2} / \mathrm{FiO}_{2}<80 \mathrm{mmHg}$ under $\mathrm{FiO}_{2}$ 1.0, positive end-expiratory pressure (PEEP) $18 \mathrm{cmH}_{2} \mathrm{O}$, and refractory to respiratory acidosis $(\mathrm{pH}<$ 7.25) despite optimized conservative therapy [15].

Bleeding is the critical problem in ECMO after cardiovascular surgery and is particularly problematic in VA-ECMO. One of the reasons is that insertion of the catheter into the artery is necessary during VA-ECMO. Another reason is the need for stricter anticoagulation management compared to VV-ECMO [16]. Herbert et al. reported a successful case of VV-ECMO in a patient off anticoagulants for a period of 20 days while being treated for hypoxemic respiratory failure caused by alveolar hemorrhage [17]. However, nafamostatmesilate-an anticoagulant-has been shown to reduce bleeding during ECMO [18] [19]. In 
the present case, there was a considerable amount of bleeding due to the effect of apixaban, but bleeding was controlled after postoperative day 2 . We also used nafamostatmesilate as an anticoagulant, and controlled activated coagulation time to around $150 \mathrm{~s}$. There were no complications associated with bleeding or thrombosis.

The blood drainage cannula size and position are important to maintain sufficient flow volume during VV-ECMO. The use of too small of a blood drainage cannula might be an important factor contributing to the poor outcomes of VV-ECMO therapy for influenza $A\left(\mathrm{H}_{1} \mathrm{~N}_{1}\right)$, an infectious disease that has been associated with severe respiratory failure in Japan [20]. The biggest point of reflection in the present case was that we used a 16.5-Fr cannula for venous drainage. We should have chosen a larger cannula for venous drainage. Extracorporeal Life Support Organization guidelinesre commend that the ventilator should be managed at low settings (low rate with long inspiratory time, low plateau inspiratory pressure, and low $\mathrm{FiO}_{2}$ ) to allow lung rest [21]. In our case, there was no hemolysis, but there was insufficient flow; therefore, it was not possible to use low settings in the ventilator.

One of the advantages of VV-ECMO is that the extracorporeal oxygenated blood can easily reach the coronary and cerebral organs, although the risk for recirculation is always present [22]. The fraction of recirculation is influenced by cannula configuration and positioning [23]. When clinically significant, recirculation may be improved by adjusting cannula position, manipulating other factors to allow for decreased flow, adding a second drainage cannula, or using a well-placed dual-lumen cannula. Typically, when two single lumen cannulas are introduced, one cannula is placed via the right internal jugular vein with the tip in the upper part of the right atrium; the other cannula is introduced via the right femoral vein, and its tip can be positioned from the iliac vein to the upper inferior vena cava. In this case, central venous catheter and Swan-Ganz catheter were introduced via the right internal jugular vein. VV-ECMO was established under venous drainage from the left femoral vein and venous returning to the patient from the right femoral vein.

The management of ALI after cardiovascular surgery is still controversial. Even though there are Japanese guidelines for the management of acute respiratory distress syndrome [24], management protocols are not always consistent. Concerning the medical therapies, the effectiveness of neutrophilelastase inhibitors has not been established [25], but there are many reports on their effectiveness for ALI after cardiothoracic surgery [26] [27]. Many reports have suggested that steroid pulse therapy is ineffective [28], while others have reported the effectiveness of low doses of corticosteroids [29]. In the present case, high-dose methylprednisolone ( $1 \mathrm{~g} /$ day) seemed to be effective. Nonetheless, it might be necessary for us to consider the appropriate timing and dosage of steroid therapy. Many previous reports recommend ventilation with high PEEP and lower tidal volumes in the management of acute respiratory distress syndrome [30] [31]. As circulatory disturbances complicate respiratory management after car- 
diovascular surgery, it would be difficult to set up such ventilation settings. It is necessary to obtain more evidence regarding the management of ALI after surgery for aortic dissection with cardiopulmonary bypass.

\section{Conclusion}

We report a case of successful treatment of ALI using VV-ECMO after surgery for aortic dissection. Thus, VV-ECMO could be considered a treatment option for severe ALI after surgery for aortic dissection.

\section{Acknowledgements}

We would like to Editage (www.editage.jp) for English language editing.

\section{Consent for Publication}

Consent was obtained from the patient to use his medical information in this manuscript.

\section{References}

[1] Committee for Scientific Affairs, The Japanese Association for Thoracic Surgery, Masuda, M., Okumura, M., Doki, Y., Endo, S., Hirata, Y., Kobayashi, J., et al. (2016) Thoracic and Cardiovascular Surgery in Japan during 2014: Annual Report by the Japanese Association for Thoracic Surgery. General Thoracic and Cardiovasucular Surgery, 64, 665-697. https://doi.org/10.1007/s11748-016-0695-3

[2] Doi, K., Kono, S., Fujiwara, Y. and Matsuda, M. (2009) Postoperative Management against Acute Lung Injury after Surgical Treatment of Type A Acute Aortic Dissection. Shinzo, 41, 1217-1221.

[3] Nakamura, H., Yamaguchi, H., Amano, A. and Nakao, T. (2013) Venovenous Extracorporeal Membrane Oxygenation Is Effective against Post-Cardiotomy Acute Respiratory Failure in Adults. General Thoracic and Cardiovasucular Surgery, 61, 402-408. https://doi.org/10.1007/s11748-013-0226-4

[4] Bignami, E., Frati, E., Meroni, R., Verzini, A., Pozzoli, A., Benussi, S., et al. (2014) Extracorporeal Venovenous Membrane Oxygenation in the Treatment of Respiratory Insufficiency Following Cardiac Surgery. Journal of Cardiac Surgery, 29, 270-273. https://doi.org/10.1111/jocs.12278

[5] Oshima, K., Kunimoto, F., Hinohara, H., Ohkawa, M., Mita, N., Tajima, Y., et al. (2010) Extracorporeal Membrane Oxygenation for Respiratory Failure: Comparison of Venovenous versus Venoarterial Bypass. Surgical Today, 40, 216-222. https://doi.org/10.1007/s00595-008-4040-Z

[6] Chen, M.F., Chen, L.W., Cao, H. and Lin, Y. (2016) Analysis of Risk Factors for and the Prognosis of Postoperative Acute Respiratory Distress Syndrome in Patients with Stanford Type A Aortic Dissection. Journal of Thoracic Disease, 8, 2862-2871. https://doi.org/10.21037/jtd.2016.10.10

[7] Müller, M.C., Tuinman, P.R., Vlaar, A.P., Tuip, A.M., Maijoor, K., Achouiti, A., et al. (2014) Contribution of Damage-Associated Molecular Patterns to TransfusionRelated Acute Lung Injury in Cardiac Surgery. Blood Transfusion, 12, 368-375.

[8] Hudson, L., Milberg, J., Anardi, D. and Maunder, R.J. (1995) Clinical Risks for Development of the Acute Respiratory Distress Syndrome. American Journal of Res- 
piratory and Critical Care Medicine, 151, 293-301.

https://doi.org/10.1164/ajrccm.151.2.7842182

[9] Zapol, W.M., Snider, M.T., Hill, J.D., Fallat, R.J., Bartlett, R.H., Edmunds, L.H., et al. (1979) Extracorporeal Membrane Oxygenation in Severe Acute Respiratory Failure. A Randomized Prospective Study. JAMA, 242, 2193-2196.

https://doi.org/10.1001/jama.1979.03300200023016

[10] Morris, A.H., Wallace, C.J., Menlove, R.L., Clemmer, T.P., Orme, J.F., Weaver, L.K., et al. (1994) Randomized Clinical Trial of Pressure-Controlled Inverse Ration Ventilation and Extracorporeal $\mathrm{CO}_{2}$ Removal for Adult Respiratory Distress Syndrome. American Journal of Respiratory and Critical Care Medicine, 149, 295-305. https://doi.org/10.1164/ajrccm.149.2.8306022

[11] Hemmila, M.R., Rowe, S.A., Boules, T.N., Miskulin, J., McGillicuddy, J.W., Schuerer, D.J., et al. (2004) Extracorporeal Life Support for Severe Acute Respiratory Distress Syndrome in Adults. Annals of Surgery, 240, 595-607.

https://doi.org/10.1097/01.sla.0000141159.90676.2d

[12] Lindén, V., Palmér, K., Reinhard, J., Westman, R., Ehrén, H., Granholm, T., et al. (2000) High Survival in Adult Patients with Acute Respiratory Distress Syndrome Treated by Extracorporeal Membrane Oxygenation, Minimal Sedation, and Pressure Supported Ventilation. Intensive Care Medicine, 26, 1630-1637. https://doi.org/10.1007/s001340000697

[13] Amako, M., Akasu, K., Oda, T., Zaima, Y. and Yasunaga, H. (2013) A Case of Acute Aortic Dissection with Severe Aortic Regurgitation Successfully Treated by Postoperative Extracorporeal Membrane Oxygenation. Japanese Journal of Vasccular Surgery, 22, 984-988.

[14] Kon, Z.N., Bittle, G.J., Pasrija, C.P., Pham, S.M., Mazzeffi, M.A., Herr, D.L., et al. (2017) Venovenous versus Venoarterial Extracorporeal Membrane Oxygenation for Adult Patients with Acute Respiratory Distress Syndrome Requiring Precannulation Hemodynamic Support: A Review of the ELSO Registry. The Annals of Thoracic Surgery, 104, 645-649. https://doi.org/10.1016/j.athoracsur.2016.11.006

[15] Schmid, C., Philipp, A., Hilker, M., Rupprecht, L., Arlt, M., Keyser, A., et al. (2102) Venovenous Extracorporeal Membrane Oxygenation for Acute Lung Failure in Adults. The Journal of Heart and Lung Transplantation, 31, 9-15. https://doi.org/10.1016/j.healun.2011.07.013

[16] Fierro, M.A., Daneshmand, M.A. and Bartz, R.R. (2017) Perioperative Management of the Adult Patient on Venovenous Extracorporeal Membrane Oxygenation Requiring Noncardiac Surgery. Anesthesiology. https://doi.org/10.1097/ALN.0000000000001887

[17] Herbert, D.G., Buscher, H. and Nair, P. (2014) Prolongedvenovenous Extracorporeal Membrane Oxygenation without Anticoagulation: A Case of Good Pasture Syndrome-Related Pulmonary Haemorrhage. Critical Care and Resuscitation, 16, 69-72.

[18] Kotani, K., Ichiba, S., Andou, M., Sano, Y., Date, H., Tedoriya, T., et al. (2002) Extracorporeal Membrane Oxygenation with Nafamostatmesilate as an Anticoagulant for Massive Pulmonary Hemorrhage after Living-Donor Lobar Lung Transplantation. The Journal of Thoraccic and Cardiovascular Surgery, 124, 626-627.

[19] Han, S.J., Kim, H.S., Kim, K.L., Whang, S.M., Hong, K.S., Lee, W.K., et al. (2011) Use of Nafamostat Mesilate as an Anticoagulant during Extracorporeal Membrane Oxygenation. Journal of Korean Medical Science, 26, 945-950.

[20] Takeda, S., Kotani, T., Nakagawa, S., Ichiba, S., Aokage, T., Ochiai, R., et al. (2012) 
Extracorporeal Membrane Oxygenation for 2009 Influenza A (H1N1) Severe Respiratory Failure in Japan. Journal of Anesthesia, 26, 650-657. https://doi.org/10.1007/s00540-012-1402-x

[21] Extracorporeal Life Support Organization (2014) Guidelines for ECMO Centers V1.8.

[22] Palmér, O., Palmér, K., Hultman, J. and Broman, M. (2016) Cannula Design and Recirculation during Venovenous Extracorporeal Membrane Oxygenation. ASAIO Journal, 62, 737-742. https://doi.org/10.1097/MAT.0000000000000440

[23] Sen, A., Callisen, H.E., Alwardt, C.M., Larson, J.S., Lowell, A.A., Libricz, S.L., et al. (2016) Adult Venovenous Extracorporeal Membrane Oxygenation for Severe Respiratory Failure: Current Status and Future Perspectives. Annals of Cardiac Anaesthesia, 19, 97-111. https://doi.org/10.4103/0971-9784.173027

[24] The Japanese Respiratory Society (2016) Guidelines for Management of ARDS.

[25] Iwata, K., Doi, A., Ohji, G., Oka, H., Oba, Y., Takimoto, K., et al. (2010) Effect of Neutrophil Elastase Inhibitor (Sivelestat Sodium) in the Treatment of Acute Lung Injury (ALI) and Acute Respiratory Distress Syndrome (ARDS): A Systematic Review and Meta-Analysis. Internal Medicine, 49, 2423-2432.

https://doi.org/10.2169/internalmedicine.49.4010

[26] Furusawa, T., Tsukioka, K., Fukui, D., Sakaguchi, M., Seto, T., Terasaki, T., et al. (2006) The Effects of a Neutrophil Elastase Inhibitor on the Postoperative Respiratory Failure of Acute Aortic Dissection. The Thoracic and Cardiovascular Surgeon, 54, 404-407. https://doi.org/10.1055/s-2006-924195

[27] Niino, T., Hata, M., Sezai, A., Yoshitake, I., Unosawa, S., Fujita, K., et al. (2010) Efficacy of Neutrophil Elastase Inhibitor on Type A Acute Aortic Dissection. The Thoracic and Cardiovascular Surgeon, 58, 164-168. https://doi.org/10.1055/s-0029-1240846

[28] Artigas, A., Bernard, G.R., Carlet, J., Dreyfuss, D., Gattinoni, L., Hudson, L., et al. (1998) The American-European Consensus Conference on ARDS, Part 2: Ventilatory, Pharmacologic, Supportive Therapy, Study Design Strategies, and Issues Related to Recovery and Remodeling. Acute Respiratory Distress Syndrome. American Journal of Respiratory and Critical Care Medicine, 157, 1332-1347. https://doi.org/10.1164/ajrccm.157.4.ats2-98

[29] Annane, D., Sébille, V., Bellissant, E. and Ger-Inf-05 Study Group (2006) Effect of Low Doses of Corticosteroids in Septic Shock Patients with or without Early Acute Respiratory Distress Syndrome. Critical Care Medicine, 34, 22-30. https://doi.org/10.1097/01.CCM.0000194723.78632.62

[30] Acute Respiratory Distress Syndrome Network, Brower, R.G., Matthay, M.A., Morris, A., Schoenfeld, D., Thompson, B.T., et al. (2000) Ventilation with Lower Tidal Volumes as Compared with Traditional Tidal Volumes for Acute Lung Injury and the Acute Respiratory Distress Syndrome. The New England Journal of Medicine, 342, 1301-1308.

[31] Dellinger, R.P., Levy, M.M., Carlet, J.M., Bion, J., Parker, M.M., Jaeschke, R., et al. (2008) Surviving Sepsis Campaign: International Guidelines for Management of Severe Sepsis and Septic Shock: 2008. Critical Care Medicine, 36, 296-327. https://doi.org/10.1097/01.CCM.0000298158.12101.41 